\title{
OPP Regimen
}

National Cancer Institute

\section{Source}

National Cancer Institute. OPP Regimen. NCI Thesaurus. Code C9936.

A chemotherapy regimen consisting of vincristine, procarbazine, and prednisone that

may be used in the treatment of certain recurrent brain tumors. 